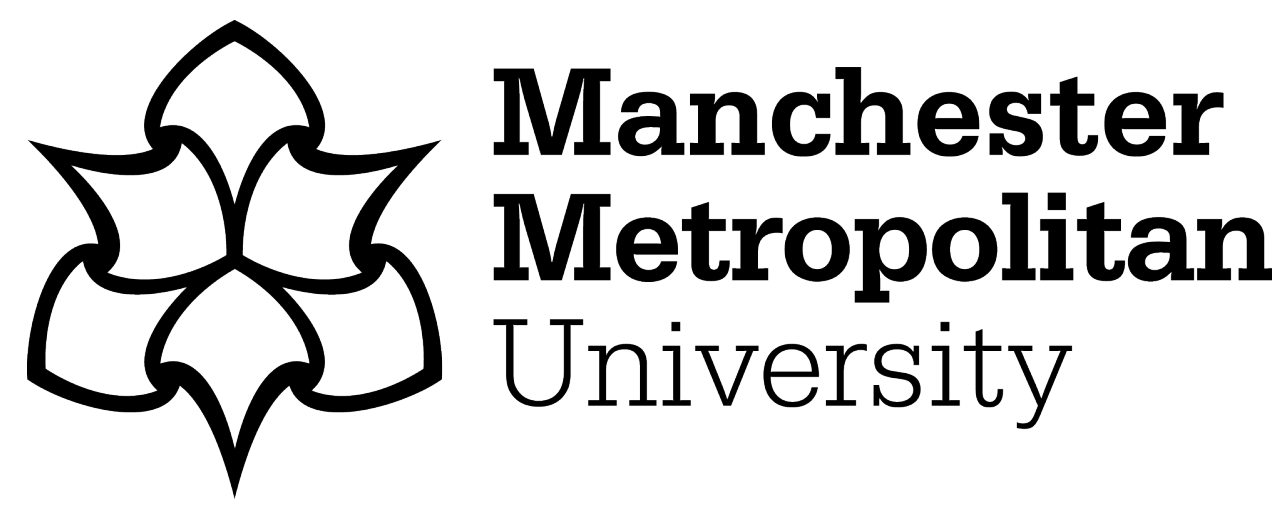

Fortune, Dónal G, Walsh, R Stephen, MacConaill, Susan, Harte, Maurice and Richards, Helen L (2021) Facilitating a return to productive roles following acquired brain injury: the impact of pre-injury work level, current abilities, and neuropsychological performance. Neuropsychological Rehabilitation, 31 (6). pp. 914-934. ISSN 0960-2011

Downloaded from: https://e-space.mmu.ac.uk/625485/

Version: Accepted Version

Publisher: Informa UK Limited

DOI: https://doi.org/10.1080/09602011.2020.1746674

Please cite the published version 


\section{Neuropsychological Rehabilitation}

\section{Facilitating a return to productive roles following acquired brain injury: The impact of pre-injury work level, current abilities, and neuropsychological performance}

\section{Dónal G. Fortune, R. Stephen Walsh, Susan MacConaill, Maurice Harte \&}

Helen L. Richards

To cite this article: Dónal G. Fortune, R. Stephen Walsh, Susan MacConaill, Maurice Harte \& Helen L. Richards (2020): Facilitating a return to productive roles following acquired brain injury: The impact of pre-injury work level, current abilities, and neuropsychological performance, Neuropsychological Rehabilitation, DOI: 10.1080/09602011.2020.1746674

To link to this article: https://doi.org/10.1080/09602011.2020.1746674

曲 Published online: 29 Mar 2020.

Submit your article to this journal $₫$

Q View related articles $\llbracket$

View Crossmark data \lceil 


\title{
Facilitating a return to productive roles following acquired brain injury: The impact of pre-injury work level, current abilities, and neuropsychological performance
}

\author{
Dónal G. Fortune ${ }^{a}$, R. Stephen Walsh ${ }^{b}$, Susan MacConaill ${ }^{c}$, Maurice Harte $^{c}$ and \\ Helen L. Richards ${ }^{d}$ \\ aDepartment of Psychology, University of Limerick, Limerick, Ireland; ${ }^{\mathrm{b}}$ Department of Psychology, \\ Manchester Metropolitan University, Manchester, UK; ${ }^{C}$ Acquired Brain Injury Ireland, Limerick, Ireland; \\ ${ }^{\mathrm{d} D e p a r t m e n t}$ of Clinical Psychology, Mercy University Hospital Cork, Cork, Ireland
}

\begin{abstract}
The primary aim of this study was to examine predictors of Return to Productive Roles (RTPR) in individuals with $A B I$ following participation in a community-based RTPR intervention. One hundred and thirty participants were inducted to an ABI-specific RTPR programme. At induction, information on clinical and social demographics, previous education and employment roles were collected. Participants underwent a comprehensive neuropsychological assessment at baseline and completed assessments of disability, mental health and community integration. Participants were followed up at the end of their programme to assess RTPR. Three out of four participants who entered the RTPR programme returned to productive roles. Despite the relatively high levels of anxiety and depression in the sample, people who returned to productive roles were not significantly less anxious or depressed than those who did not. Logistic regression suggested that participants who returned to productive roles following the programme had higher levels of pre-ABI work engagement, less disability and performed better on neuropsychological assessment in terms of their language skills. Results suggest that these factors which cut across specific prior experience, cognitive performance, and social and disability areas of functioning represent barriers to an effective return to productive roles for people with $\mathrm{ABI}$ accessing RTPR intervention.
\end{abstract}

\section{ARTICLE HISTORY}

Received 13 June 2019

Accepted 18 March 2020

KEYWORDS

Brain injury; rehabilitation; employment; neuropsychological assessment; disability

\section{Introduction}

Acquired brain injury $(A B I)$ is the leading cause of disability in people of working age. The consequences of $A B I$ which may include cognitive, emotional, social and behavioural impacts present a substantial obstacle to recovery and community participation and integration following injury (Brasure et al., 2013; Cicerone et al., 2004). A productive lifestyle is a major problem area for many individuals 
following $\mathrm{ABI}$ and one of the most compelling long-term challenges for individuals is finding and maintaining employment or engaging with other productive roles such as education or voluntary work (Ownsworth \& McKenna, 2004; Saltychev et al., 2013; Schonbrun \& Kampfe, 2004; van Velzen et al., 2009a; Willemsevan Son et al., 2007). Given that the ultimate goal of rehabilitation is participation in society and community integration, return to productive roles (RTPR) is a key marker of the success of rehabilitation endeavours (McCrimmon \& Oddy, 2006).

Rates of people returning to productive roles following brain injury show considerable variation: in general approximately half of people who sustain an $A B I$ return to work or education (Odgaard et al., 2017; Sigurdardottir et al., 2020; Ponsford et al., 2014; Ponsford \& Spitz, 2015; van Velzen et al. 2009b). It is also recognized that if people have not returned to productive roles within 1-2 years post injury, they are less likely to do so without specialized intervention (Ruet et al., 2018; Treger et al., 2007; van Velzen et al. 2009a).

Predicting which individuals will experience problems in RTPR has proved somewhat difficult, and thus identifying which individuals may actually benefit from interventional approaches is challenging (Franulic et al., 2004; Grauwmeijer et al., 2012; Simpson et al., 2018). A number of factors have been suggested as potentially important in accounting for RTPR, ranging from injury characteristics, sociodemographic factors, post-injury cognitive functioning and mental health challenges.

The effects of initial injury severity on RTPR tend to be somewhat unclear. For example, while a review of 80 published studies (Saltychev et al., 2013) reported that reduced RTPR was related to loss of consciousness (LOC), duration of posttraumatic amnesia (PTA) and acute admission, other reviews (Donker-Cools, Wind, et al., 2016; Ownsworth \& McKenna, 2004; van Velzen et al., 2009a) have found no significant role for initial severity assessments in $A B I$ in predicting RTPR.

The published evidence that neuropsychological difficulties in particular domains of functioning impact on return to productive roles is also somewhat mixed. This may result from the small numbers of available studies that have used consistent formal neuropsychological assessments. The cognitive functions that have been most strongly associated with RTPR tend to be speed of information processing (Fabiano \& Crewe, 1995; Girard et al., 1996; Machamer et al., 2005; Sigurdardottir et al., 2020), memory and working memory (Dawson et al., 2004; Johansson \& Bernspang, 2001; Li-Wood \& Rutterford, 2006), broader aspects of executive function (Kauranen et al., 2013; Ownsworth \& McKenna, 2004; Rietdijk et al., 2013; Sawamura et al., 2018), and a general cognitive functioning factor (van der Kemp et al., 2019).

In addition to cognitive challenges, there is also some evidence to suggest that post-injury mental health difficulties may be related to RTPR in $A B I$, in so far as people who have sustained an $A B I$ and are in employment have lower levels of depression and anxiety than people with $A B I$ not in work (Franulic et al., 2004; Ownsworth \& McKenna, 2004). While in general there are a 
paucity of studies examining anxiety and depression (e.g., van Velzen et al., 2009a) more recent research has identified a negative association between comorbid psychological difficulties and RTPR for people with an ABI (DonkerCools, Daams, et al., 2016; Garrelfs et al., 2015; van der Horn et al., 2013). Given the likely impact of $A B I$ on psychological functioning, further studies are required to evaluate the role of mental health in RTPR.

Re-engaging with employment or other productive roles can be a significant challenge for people living with $\mathrm{ABI}$, thus the development of specific interventions to address such challenges is an important undertaking. To date the results from systematic reviews of published interventional studies relating to return to productivity following brain injury have not revealed consistent results (DonkerCools, Wind, et al., 2016; Ownsworth \& McKenna, 2004; Saltychev et al., 2013; Schonbrun \& Kampfe, 2004; van Velzen et al. 2009a; Willemse-van Son et al., 2007). For example, van Velzen et al. (2009a) and Willemse-van Son et al. (2007) found no significant evidence of an improvement in outcome; Saltychev et al. (2013), found that six out of their ten studies reviewed either did not find any difference between the effects of particular interventions on outcomes or their effect was not long term, while four small studies found positive effects of the interventions. Ownsworth and McKenna (2004) found that engagement in intervention predicted employment following brain injury, although the effect was moderate. Given the suggestion that the probability of re-entering employment remains relatively stable up to 10 years following brain injury (Howe et al., 2018), there is a continuing need to examine predictors of return to productive roles particularly in people in receipt of ABI-specific RTPR intervention.

\section{Aims and hypotheses}

The current study aimed to better understand factors that may promote RTPR in people with $A B I$ in receipt of an individualized intervention to promote RTPR. We hypothesized that return to productive roles would be predicted by lower indices of anxiety and depression, followed by better performance on executive functioning irrespective of patient's general neuropsychological performance. We also predicted that the level at which the person was employed prior to their brain injury would be an important factor in current level of RTPR. The current study should add important information about predictors of return to productive roles when ABI-specific RTPR support is maximized.

\section{Methods}

The participant data is part of a prospective cohort study of return to productive roles in $\mathrm{ABI}$ in the context of a specific RTPR intervention. 


\section{Participants and procedure}

Participants were 134 people with $A B I$ who were referred to an ABI-specific RTPR intervention across 3 community area hubs in areas of disadvantage in the Republic of Ireland (Border, Midlands and West of Ireland). See Figure 1 for the flow of participants to the study. Four participants had missing data on their measures $(>25 \%)$, resulting in a final sample of 130 participants who were aged between 18 and 57 years (Mean 38.8; SD 10.7). Duration since injury ranged from 1 year to 15 years (mean 6.20; SD 4.73). Thirty per cent $(n=39)$ had sustained their injury less than 2 years previously, $27 \%(n=35)$ between 2 and 5 years previously, 21.5\% $(n=28)$ between 6 and 10 years previously, and

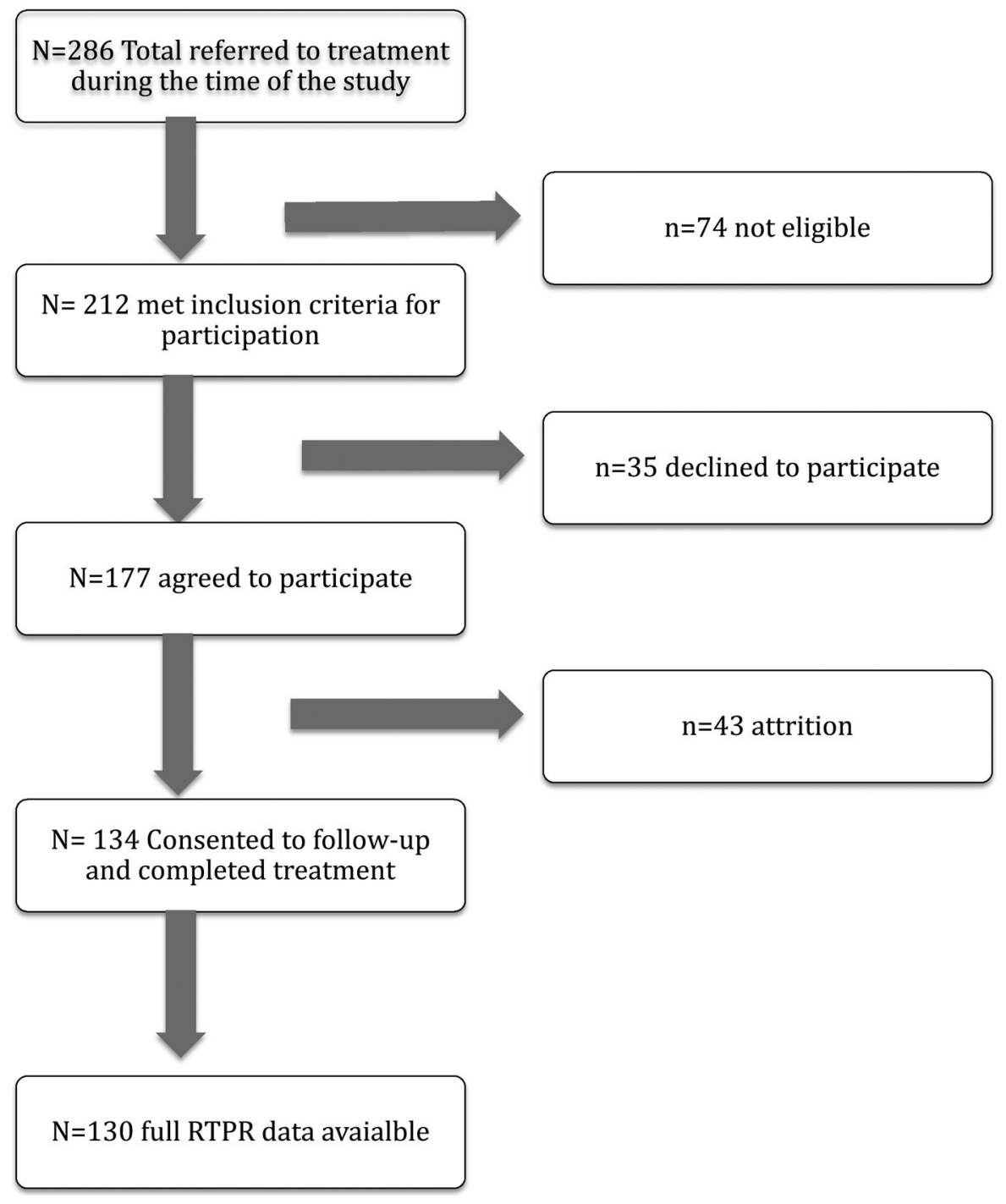

Figure 1. Flow of participants to the study. 
21.5\% ( $n=28$ ) between 11 and 15 years previously. The majority of participants were male (71.5\%).

Individuals were eligible for participation if the person (a) had a documented $A B I$, (b) was aged 18 years or over, (c) was judged by their clinical team as able to decide on informed consent, and (d) reported intending to return to productive roles.

\section{Procedure}

The research protocol was approved by the local research ethics committee and all participants provided written informed consent. The study adhered to standardized reporting guidelines for cohort studies (STROBE).

\section{Overview of the project and the Work4You programme}

The Work4You programme is a pilot community-based support service focusing on vocational, educational and social reintegration and designed to maximise the capacity of people with an $A B I$ to re-enter the workforce or other productive roles (i.e., paid employment, education, or voluntary work as a training platform) in the Border, Midlands, and Western Regions of the Republic of Ireland. Thus the programme is a community re-entry programme that focuses on vocational and social reintegration (Graham et al., 2016). The programme explored areas of realistic work, training or education options, seeking to build a bridge between the individual, their potential job/educational role and potential employment/educational opportunities. Specifically, the Work4You project provided individuals with three dedicated work packages initially in a 1: 1 context: (1) A vocational assessment service to identify strengths and needs resulting from the person's brain injury. This assessment included an idiosyncratic formulation approach to participant's needs including SWOT analysis, and in cases where the initial assessment suggested the participant may benefit, a formal assessment utilizing various protocols including Valpar assessment; (2) a workplace/education environmental analysis to identify the pragmatic and situation-specific barriers and supports required to return to productive roles, and (3) an individualized Personal Progression and support plan to meaningfully address strengths and needs and delineate the measures necessary to support RTPR. Specifically, the collaborative agreement with the client as part of the Personal Progression Plan (PPP) included:

- Liaison/Collaboration with all relevant stakeholders (families where appropriate, employers, educational institutions, workplace placement providers etc)

- Workplace/Education environmental assessment with participant

- Workplace/Education environmental assessment in collaboration with all beneficiaries (potential employers, educational institution, work placement 
providers etc), followed up at timepoints agreed with both participant and employer/educational institution/work placement provider.

- Development of PPP's commensurate with need.

- Complete meaningful goals on PPPs supported by Programme team. PPP reviews were held at 3, 6 and 12 month time points.

- Reduce, withdraw and evaluate each participant's service to ensure the development of independence goals.

- Contact coaching (where staff supported the participant while collaboratively working to gradually increase independence) was maintained with all individuals in a supportive context throughout the Work4You project. Duration of contacts was based on individual client formulation. The programme was delivered by three Vocational Assessment Teams in the Border, Midlands and Western Region of Ireland, with each of the 3 teams consisting of a senior grade Occupational Therapist and two $\mathrm{ABI}$ Community Rehabilitation Assistants.

\section{Assessments at induction to the programme}

\section{Sociodemographic data}

Socio-demographic information was collected at baseline including the participant's age, gender, educational attainment, employment history (i.e., employment prior to $A B I$ ), their current relationship status, current living circumstances, nature of their $A B I$, age at which they sustained their $A B I$, and the time since their injury.

\section{Disability - Mayo Portland Adaptability Inventory (MPAI-4).}

We utilized the MPAI-4 (Malec \& Lezak, 2008) as our index of severity of injury impact. The heterogenous nature of the brain injury sample and the well documented issues with poor prediction over time for the Glasgow Coma Scale and well-recognized treatment issues at the time of injury (prehospital sedation and tracheal intubation) have been reported to confound such simple measures of injury (Balestreri et al., 2004; Maas et al., 2017). By contrast, the MPAl-4 yields a total score reflecting overall disability, as well as 3 subscale scores for the Ability Index (e.g., mobility, cognitive functioning, communication), Adjustment Index (e.g., pain, mood, fatigue), and Participation Index (e.g., social contact, independent living, employment). Higher scores on each of the subscales indicate greater disability. Prior studies have demonstrated satisfactory internal consistency and construct validity, as well as concurrent and predictive validity, for the full measure and its indices (Kean et al., 2011; Malec et al., 2012), and measures of MCID and RCID have been published (Malec et al., 2017). The MPAl-4 has been shown to be sensitive to clinical change in studies of general community rehabilitation interventions in the Republic of Ireland (Fortune et al., 2015). Cronbachs alpha was 0.81, 0.90 and 0.78 for the Abilities, Adjustment and Participation subscales respectively. 


\section{Hospital Anxiety and Depression Scale}

Anxiety and depression were assessed by the 14 item Hospital Anxiety and Depression Scale (HADS; Zigmond \& Snaith, 1983). The HADS has been widely used in studies with patients with brain injury and has been shown to be an appropriate measure of anxiety and depression (Dawkins et al., 2006; Schonberger \& Ponsford, 2010). A score of $>7$ on either scale indicates the presence of clinically relevant distress. Internal consistency (Cronbach's a) for the anxiety and depression subscales in the current sample were 0.86 and 0.77 respectively.

\section{Community Integration Questionnaire (CIQ)}

Community Integration of participants was assessed by use of the 15 item Community Integration Questionnaire (CIQ; Corrigan \& Deming, 1995). The CIQ assesses effective role performance in three domains: Home integration (active participation in the operation of the home or household), Social integration (participation in social activities outside the home) and Productivity (regular performance of work, school or volunteer activities). Internal consistency in previous studies has been reported as good, with Cronbach's alpha's ranging from 0.76 to 0.84 for total scale scores (Corrigan \& Deming, 1995; Fortune et al., 2016). The CIQ is predominately linked to the major life areas (35\%), community, social and civic life (31\%) and domestic life (19\%) chapters of the WHO ICF (Salter et al., 2011). Internal consistency of the total scale was 0.69.

\section{Neuropsychological assessment}

\section{Repeatable battery for assessment of neuropsychological status (RBANS)}

The RBANS (Randolph, 1998) is a brief cognitive screening battery consisting of 12 subtests which are used to create Index scores in the following five cognitive domains: Immediate Memory, Visuospatial/Constructional Skills, Language, Attention, and Delayed Memory. A total score is created by summing the five index scores. Research has supported the clinical application of the RBANS as a neuropsychological tool within various populations including moderate to severe traumatic brain injury (Lippa et al., 2013; McKay et al., 2007), and stroke disorder (Larson et al., 2005; Wilde, 2010).

\section{Executive functioning}

\section{Biber COGNITIVE Estimation Test (B-CET)}

Estimation abilities were assessed by the 20 item Biber Cognitive Estimation Test (B-CET; Bullard et al., 2004). The B-CET assesses estimation abilities in relation to time/duration, quantity, weight, and distance, and has been demonstrated to possess good internal reliability in people with $\mathrm{ABI}$. Higher scores contribute to better self-reported community integration (Fortune \& Richards, 2017). 


\section{Phonemic and semantic fluency}

Verbal fluency (phonemic fluency) was assessed by the FAS test and Semantic/ category fluency by fruits, vegetables and animals. Verbal fluency has been shown to predict a return to work following brain injury (Drake et al., 2000).

\section{Trail making test $A \& B$}

The TMT was used to measure cognitive and motor speed (TMT-A) and mental flexibility (TMT-B). There are a number of derived scores for the TMT and in the current study the B-A difference score and the B/A ratio score were used (Lamberty et al., 1994; Sánchez-Cubillo et al., 2009).

\section{Level of return to productive roles}

The primary outcome was return to work or productive activity (i.e., paid work, education, or engagement in voluntary work or work placement as a stepping stone to paid work) as assessed by a senior occupational therapist.

The Standard Occupational Classification 2000 (SOCv2000), (UK Office for National Statistics, 2008) was used to code pre-injury and post-intervention vocational skill levels. The coding system used by the Irish Central -Statistics Office utilizes SOC codes as part of their 9 factor taxonomy (Managers to elementary occupations; (CSO, 2015)). For reasons of parsimony and to increase interpretability in this current report, it was therefore decided to utilize the SOC codes in their more parsimonious state. The skill levels, therefore, range from 1 to 4 as below:

- Level 1 skills include elementary trades such as plant and storage occupations, elementary administration and service occupations.

- Level 2 skills include administrative, secretarial, personal caring, sales, leisure, customer services, process, plant and machine operatives

- Level 3 skills include health and social welfare professions, managers and proprietors in agriculture and services, science and technology associated professionals, cultural, media and sport occupations

- Level 4 skills include corporate managers, science, technology, health professionals, teaching and research professions

Students were classified according to the job defined by their programme when they would complete their studies. Commensurate with previous research (e.g., Radford et al., 2013), in cases where there was no clear vocational outcome, students were classified as level 3.

\section{Statistical analysis}

Kolmogorov-Smirnov and Q-Q plots were used to evaluate deviations from normality, and checks were carried out to ensure that there was no violation of the 
assumptions of normality, linearity, homogeneity of variances, and homogeneity of regression slopes. Differences in mean scores at induction were calculated by independent samples t-test (bootstrapping for non-normally distributed variables) and Analysis of Variance models for continuous data. Categorical variables were analysed by Chi square test $\left(x^{2}\right)$. Correlations were examined by pearsons correlation coefficient. We did not seek to formally correct for multiple univariate tests as tests related to different hypotheses (Bender \& Lange, 2001; Silverberg et al., 2018). Variables that were significantly associated with return to productive roles were entered in a Logistic regression analysis. Multicollinearity was set at $r$ $>0.7, a$ for inclusion at $<0.05$, and results are reported with $95 \%$ confidence intervals where available.

\section{Results}

\section{Educational attainments}

The majority of participants $(45.4 \%, n=59)$ had attained up to junior certificate (approx. 11 years education). Leaving certificate qualifications (approx. 14 years education) were attained by $34.6 \%$ of participants $(n=45)$. One in 5 participants $(n=26)$ had a post-graduate qualification.

\section{Pre-injury productive roles}

Prior to their injury, $28.5 \%$ of participants $(n=37)$ were in Level 1 occupations (e.g., elementary trades, plant and storage occupations, elementary administration and service occupations), the majority of participants ( $n=$ 72, 55.4\%) were engaged in employment at level 2 (e.g., administrative, secretarial, personal caring, sales, leisure, customer services, process, plant and machine operatives), 14 (10.7\%) \% in Level 3 occupations (e.g., health and social care professions, managers and proprietors in agriculture and services, science and technology associated professionals, cultural, media and sport occupations), 6 (4.6\%) of participants were unemployed. Only 1 person was employed at Level 4 (e.g., corporate managers, science, technology, health professionals, teaching and research professions). For parsimony, two pre-injury employment groups comprising (a) elementary trades/ admin/ roles, and (b) skilled and professional roles were created using SOC skill groupings.

\section{Relationship status}

The majority of participants described themselves as single $(56 \%, n=73)$. Onethird of participants $(n=44)$ were married or in a committed relationship, and an additional $10 \%(n=13)$ were separated, divorced or widowed. 


\section{Current living circumstances}

Most participants $(71.5 \% ; n=93$ ) lived with family (e.g., their parents, partner/ spouse or other family members, such as adult children and siblings). Over one in five $(22.3 \% ; n=29)$ were living alone, and $6 \%(n=8)$ living in supported accommodation.

\section{Cause of $A B I$}

Method of Brain Injury was predominantly Traumatic Brain Injury $(62 \% ; n=81)$, followed by Stroke $(29 \%, n=37)$, Neoplasm $(2.3 \% ; n=3)$, Anoxia $(4.6 \% ; n=6)$ and Encephalitis $(2.3 \% ; n=3)$. For parsimony, 3 categories were created for subsequent analysis: Traumatic brain injury, Stroke, and a third category comprising neoplasm, anoxia, and encephalitis $(9.2 \% ; n=12)$.

\section{Anxiety and depression}

Scores on the HADS Anxiety subscale ranged from 0 to 21 (mean 7.09; SD 4.7). Scores on the HADS depression subscale ranged from 0 to 17 (mean 5.94; SD 3.87) Using the published clinical cut-offs for anxiety and depression (HADS $>7), 40.7 \%$ of the sample $(n=53 / 130)$ were experiencing clinically relevant anxiety symptoms, while $35.4 \%(n=46 / 130)$ were experiencing clinically relevant symptoms of depression.

\section{Community integration}

Scores on the Community Integration Questionnaire ranged from 4 to 24 (mean 15.8, SD 4.83).

\section{Disability}

The MPAI-4 T scores ranged from 4 to 64 for Ability (mean 45.25, SD 10.44), 4-65 for Adjustment (mean 43.66, SD 14.36), and 3-74 for Participation $(M=42.24$; 13.19). Total MPAI-4 score ranged from 14 to 63 (mean 46.72, SD 9.14).

\section{Proportion of people returning to productive roles}

A total of $75 \%$ of participants had re-entered productive roles following the Work4You programme. Table 1 shows participants level of productive role prior to their $\mathrm{ABI}$ and following participation in the programme.

Figure 2 outlines the roles entered by individuals following the intervention.

The most frequent skill level at which individuals re-entered productive roles for paid employment, education and work placements were Level 2 (e.g., 
administrative, secretarial, personal caring, sales, leisure, customer services, process, plant and machine operatives). Level 1 occupations (e.g., elementary trades, plant and storage occupations, elementary administration and service occupations), was the next highest level for paid employment but was the lowest for education and work placements. Level 3 skills (e.g., health and social care professions, managers and proprietors in agriculture and services, science and technology associated professionals, cultural, media and sport occupations) were well represented particularly in education and voluntary work/ work placements. In the current sample, no person re-entered productive roles at Level 4 (e.g., corporate managers, science, technology, health professionals, teaching and research professions etc).

There was no significant difference on likelihood of RTPR between people who sustained their $\mathrm{ABI}$ more than 6 years previously compared to people who sustained their injury 5 years or less $\left(x^{2}=.10, p=.74\right)$. Similarly for participants who returned to RTPR there was no significant difference between these two duration groups on the SOC level at which they entered work, education or voluntary role $\left(x^{2}=3.02, p=.38\right)$.

Table 2 reports the univariate results for people who did vs did not RTPR over the time period of their intervention.

The results from the assessment measures taken at induction to the programme for people who returned to productive roles versus those who did not are presented below (Table 3).

\section{Summary of univariate analyses}

Participants who returned to productive roles at the end of their specialist rehabilitation programme had a higher level of productive roles prior to their injury, less disability (Abilities and Participation), better neuropsychological function, in terms of their visuospatial and language skills, and better community integration at induction to the programme when compared with participants who did not return to productive roles over the course of their RTPR programme.

\section{Logistic regression}

Variables entered into the Multivariate logistic regression analysis were previous level of productive roles, current visuospatial/constructional abilities, current

Table 1. Participants SOC codes for productive roles ${ }^{\mathrm{a}}$ prior to $\mathrm{ABI}$ and following the Work4You programme.

\begin{tabular}{lllllc}
\hline & Not in a productive role & SOC Level 1 & SOC Level 2 & SOC Level 3 & SOC Level 4 \\
\hline Prior to ABI & $6(4.6 \%)$ & $37(28.5 \%)$ & $72(55.4 \%)$ & $14(10.7 \%)$ & $1(0.8 \%)$ \\
Post programme & $33(25.4 \%)$ & $16(12.3 \%)$ & $57(43.8 \%)$ & $24(18.5 \%)$ & 0 \\
\hline \multicolumn{2}{l}{ a Productive role = paid employment, education or work placement }
\end{tabular}


30

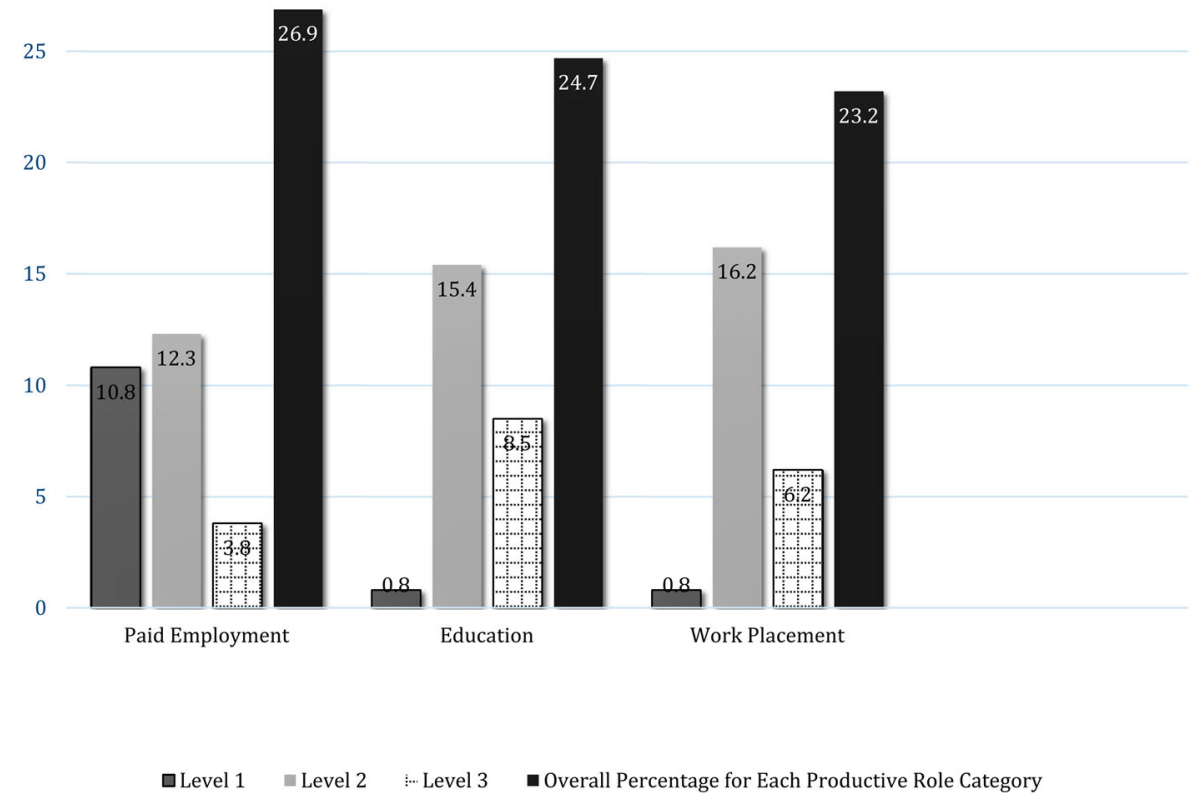

Figure 2. Participants (\%) entering particular productive roles and associated skill levels following the Work4You intervention.

Table 2. Univariate analyses for people who returned to productive roles vs those who did not.

\begin{tabular}{|c|c|c|c|c|}
\hline Variable & RTPR & Did not RTPR & Statistics & $P$ \\
\hline \multicolumn{5}{|l|}{ Demographics } \\
\hline Age (mean SD) & $39.55(10.62)$ & $31.85(13.14)$ & $t=0.41$ & .68 \\
\hline Female $(n, \%)$ & $28(28.86)$ & $9(27.3)$ & & \\
\hline Male $(n, \%)$ & $69(71.13)$ & $24(72.7)$ & $x^{2}=0.86$ & .52 \\
\hline \multicolumn{5}{|l|}{ Education } \\
\hline Junior certificate $(n, \%)$ & $43(44.33)$ & $16(48.49)$ & & \\
\hline Leaving certificate $(n, \%)$ & $34(35.05)$ & $11(33.33)$ & & \\
\hline Third level $(n, \%)$ & $20(20.62)$ & $6(18.18)$ & $x^{2}=0.18$ & .67 \\
\hline \multicolumn{5}{|l|}{ Clinical demographics } \\
\hline Age at injury & $32.56(12.07)$ & $32.42(14.60)$ & $t=0.56$ & .95 \\
\hline Time since injury & $6.02(4.65)$ & $6.75(5.0)$ & $t=0.77$ & .44 \\
\hline \multicolumn{5}{|l|}{ Nature of $A B I$} \\
\hline $\mathrm{TBI}(n, \%)$ & $61(75.3)$ & $20(60.6)$ & & \\
\hline Stroke $(n, \%)$ & $28(62.9)$ & $9(27.3)$ & $x^{2}=0.42$ & .81 \\
\hline Other $(n, \%)$ & $8(8.2)$ & $4(12.1)$ & & \\
\hline \multicolumn{5}{|l|}{ Current Relationship status } \\
\hline Single $(n, \%)$ & $56(57.73)$ & $18(54.54)$ & $x^{2}=1.22$ & .54 \\
\hline In a relationship or married $(n, \%)$ & $33(34.02)$ & $10(30.30)$ & & \\
\hline Separated, divorced, widowed ( $n, \%)$ & $8(8.25)$ & $5(15.15)$ & & \\
\hline \multicolumn{5}{|l|}{ Current Living Circumstances } \\
\hline Alone $(n, \%)$ & $23(23.7)$ & $6(18.1)$ & $x^{2}=0.72$ & .86 \\
\hline With family $(n, \%)$ & $38(40.2)$ & $15(45.5)$ & & \\
\hline With spouse/partner $(n, \%)$ & $30(32.0)$ & $10(30.3)$ & & \\
\hline Sheltered/supported housing ( $n, \%)$ & $5(5.1)$ & $3(8.1)$ & & \\
\hline \multicolumn{5}{|l|}{ Previous Level of Productive Role } \\
\hline SOC group 1 Elementary trades/admin/ roles & $37(28.5 \%)$ & $06(4.5 \%)$ & $x^{2}=4.43$ & .03 \\
\hline SOC group 2 Skilled and professional roles & $60(46.2 \%)$ & $27(20.8 \%)$ & & \\
\hline
\end{tabular}


Table 3. Univariate analyses of neuropsychological, disability, community integration and psychological distress scores for RTPR and participants who did not RTPR.

\begin{tabular}{lcccc}
\hline Variable & RTPR & Did not RTPR & Statistics & $P$ \\
\hline $\begin{array}{l}\text { Repeatable Battery for Assessment of Neuropsychological Status } \\
\text { Immediate memory }\end{array}$ & $73.31(20.58)$ & $70.19(19.04)$ & $t=0.79$ & .43 \\
Visuospatial/constructional & $84.06(20.16)$ & $74.79(17.65)$ & $t=-2.08$ & .04 \\
Language & $81.32(13.52)$ & $73.88(20.01)$ & $t=-2.12$ & .03 \\
Attention & $80.55(18.74)$ & $73.00(19.39)$ & $t=-1.92$ & .06 \\
Delayed memory & $70.34(18.49)$ & $72.87(19.38)$ & $t=.55$ & .96 \\
Total Score & $73.58(15.53)$ & $68.76(16.63)$ & $t=-1.35$ & .18 \\
Cognitive estimation & & & & \\
Biber Cognitive Estimation Test & $14.86(2.99)$ & $14.77(2.78)$ & $t=-0.15$ & .88 \\
Verbal Fluency & & & & \\
Phonemic fluency & $23.67(10.72)$ & $22.77(11.79)$ & $t=-0.39$ & .69 \\
Semantic fluency & $14.19(4.57)$ & $16.35(4.34)$ & $t=-1.20$ & .23 \\
Trail Making Test & & & & \\
TMT A & $52.70(40.97)$ & $63.94(34.25)$ & $t=1.50$ & .13 \\
TMT B & $195.97(166.50)$ & $213.06(178.22)$ & $t=1.13$ & .26 \\
TMT ratio score & $3.96(3.90)$ & $3.88(3.15)$ & $t=-0.39$ & .69 \\
TMT difference score & $143.26(155.94)$ & $149.12(175.14)$ & $t=0.67$ & .50 \\
Disability - MPAl - 4 & & & & \\
MPAI abilities & $9.28(5.96)$ & $13.68(7.24)$ & $t=3.34$ & .001 \\
MPAl adjustment & $13.26(10.36)$ & $15.21(11.03)$ & $t=0.91$ & .36 \\
MPAI participation & $12.27(7.77)$ & $16.21(8.89)$ & $t=2.39$ & .01 \\
Community integration & & & & \\
Community integration questionnaire & $15.55(4.35)$ & $13.59(4.85)$ & $t=2.02$ & .04 \\
Psychological distress & & & & \\
HAD anxiety subscale & $7.16(4.65)$ & $6.88(4.82)$ & $t=-0.30$ & .76 \\
HAD depression subscale & $5.88(6.97)$ & $6.12(3.94)$ & $t=0.31$ & .24 \\
\hline
\end{tabular}

language functioning, physical abilities, and social participation. Examination of the potential for significant interacting effects did not discern any significant interaction. The multivariate logistic regression analysis suggested that the model was statistically significant $\left(x^{2}=22.59 ; p<.001\right)$. Of these 5 variables entered, 3 independent predictors of RTPR made unique and significant contributions to the model (Table 4).

Higher previous level of productive role (odds ratio $[\mathrm{OR}]=15.78 ; 95 \%$ confidence interval $[\mathrm{Cl}] 1.90-31.01, p<.01)$, less physical disability $(\mathrm{OR}=0.88, \mathrm{Cl}=$ $0.81-0.95, p<.01$ ), and better language skills ( $\mathrm{OR}=1.04, \mathrm{Cl}=1.00-1.07, p<.01$ ) predicted RTPR. The result of the Hosmer-Lemeshow analysis was not statistically significant $(p>.05)$, suggesting a good fit of the model. The model explained $35 \%$ of the variance in RTPR (Nagelkerke $R^{2}=0.352$ ).

\section{Discussion}

This is one of the first studies to examine the effects of providing an intervention to facilitate return to productive roles following $A B I$ in a community setting and

Table 4. Multivariate logistic regression analysis of RTPR.

\begin{tabular}{lcccccr}
\hline Variable & $B$ & SE & Wald & $p$ & OR & $95 \% \mathrm{Cl}$ \\
\hline Pre-injury productive role & 2.759 & 1.080 & 6.528 & .01 & 15.78 & $1.90-31.01$ \\
MPAl-4 Physical abilities & -0.126 & 0.042 & 9.104 & .003 & 0.882 & $0.81-0.95$ \\
RBANS Language index & 0.043 & 0.018 & 6.051 & .014 & 1.044 & $1.00-1.08$ \\
\hline
\end{tabular}


across geographical areas not usually well-served by such interventions (i.e., outside of major towns and cities).

Three out of 4 participants in this study returned to a productive role, with $27 \%$ of the current sample engaging in paid employment, $25 \%$ entering education and $23 \%$ entering voluntary/training work placement.

There was a significant association between return to productive roles and previous work levels, with people who were employed at higher work levels prior to their injury being more likely to return to some form of productive role following the Work4You intervention. This higher rate of RTPR in people who were employed at higher work levels builds on previous work which suggested that people who were from lower SOC codes prior to their injury (e.g., machinery operators or labourers) showed greater employment instability since their injury (Ponsford \& Spitz, 2015). Previous research has suggested that prior educational attainment may underpin this issue (Wang et al., 2019). However, while education seems to have an additive effect in more generic Home and Community rehabilitation programmes, serving to strengthen the effects of rehabilitation in this context (Fortune et al., 2016), in the current study educational attainment did not significantly influence RTPR.

The effects of greater physical disability on RTPR is self-evident and despite the move towards equitable access to work or education regardless of disability, greater physical disability would likely limit the potential avenues available for RTPR. Similarly the poorer community integration and participation observed at induction in people who did not return to productive roles is concerning, and may be related to a broad array of ABI-related physical effects. Indeed while the correlation between greater disability and community integration was moderately significant $(r=-0.23)$, the association between greater disability and Participation was highly significant $(r=0.61)$. This probably reflects differences in the specific nature of the CIQ and MPAI participation indices and suggests that these constructs and the measures that operationalize them are not necessarily interchangeable. The current programme through the use of PPP sought to provide meaningful goals that may help with engagement, motivation and participation. Meaningful activities through such goals are important as they tend to result in a closer fit with participants experiences in terms of competence, personal control, purpose and positive emotions (Eakman et al., 2018). While research suggests the importance of supporting meaningful activities in terms of rehabilitation endeavours and more complex interventional approaches (Jamieson et al., 2019), for a substantial minority of people with $A B I$ there would appear to exist a vicious cycle of initial low community integration or participation hampering the potential for RTPR to enhance a person's meaningful participation in their community. Enhancing community integration is challenging in post-acute rehabilitation services and it has previously been demonstrated that while other aspects of a person's experience (e.g., distress, disability, and 
quality of life) improve over the course of post-acute community neurorehabilitation, community integration may remain stagnant (Fortune et al., 2015).

The current evaluation found Language and Visuospatial difficulties significantly over-represented in the group who did not RTPR, with language difficulties remaining significant in the final regression model. Such pragmatic difficulties would likely be significant barriers to engagement with the majority of types of employment, study or voluntary training work available. It should be additionally noted however, that in general, the entire cohort of participants comprised individuals who were quite cognitively affected by their $A B I$, with only $20 \%$ of the entire sample of participants scoring above the 16 th percentile in terms of their general cognitive functioning (immediate and delayed memory, language, attention, spatial skills) as assessed by the RBANS. Nonetheless the specific effects of language challenges which are likely to make the effects of an $\mathrm{ABI}$ on the person more socially and interpersonally visible seem to be particularly salient in terms of RTPR.

Despite the relatively high levels of psychological distress in the current sample (clinically relevant anxiety was experienced by more than $40 \%$ of participants, and clinically-relevant depression was experienced by some $35 \%$ of participants) we did not find any significant effect of psychological distress on RTPR. This was surprising as a number of previous studies have suggested a role for mental health issues in reducing opportunities for engagement or re-engagement with productive roles (Franulic et al., 2004; Garrelfs et al., 2015; van der Horn et al., 2013). Bonner et al. (2016) reported no effect of distress on return to work rates, while Silverberg et al. (2018) reported that comorbid depression and anxiety were high even in those who returned to work following mild TBI. In the current study, it may have been the case that the level of contact and follow-up by the RTPR-specific teams, may have been sufficiently containing for clients accessing the programme, thus enabling such challenges not to become additional barriers to engagement with RTPR.

This examination of a cohort in receipt of an ABI-specific RTPR intervention has demonstrated that 3 out of 4 individuals who subsequently participated in the intervention were engaged in productive roles at follow-up. This figure compares very well with published research combining specific vocational rehabilitation with community neurorehabilitation following $A B I$ (thereby producing a significantly more comprehensive service) and which suggest a return to productive roles of approximately $60 \%$ (Ntsiea et al., 2015). While the current study is a cohort study, the current figures of the Work4You service compare very well to such outcome data.

In terms of limitations of this study, this is a cohort study and care must be exercised in drawing conclusions that intervention alone may be responsible for the outcomes observed. Secondly, while the number of participants in the current study reflects other studies in this field, the number of participants 
who did not RTPR ( $25 \%$ of the sample) was too low for detailed additional analysis. While our assessment protocol included 3 cognitive measures that are commonly used as assessments of executive function, it would have been helpful to include more ecologically valid measures of EF that may have provided additional information on the impact of EF on outcomes. Similarly, we utilized the MPAI-4 as our index of functional impact/severity of ABI. While we believe this was a good fit for the nature of this study, future studies would benefit from the addition of clinical severity data such as the Mayo classification approach where viable. Longer follow-up times are also necessary to examine the stability of participants RTPR and whether the group who did not achieve a RTPR over the time period of this study represented a stable RTPR. Finally, while data on living situation and relationship status was included in the protocol as proxies for environmental influences and social support outside of the intervention, broader environmental aspects of participants experience were not available. For example, fine-grained local rates of employment are likely to have impacted upon availability of avenues for RTPR. Similarly, rural versus more urban environments again would likely affect RTPR through availability and access to avenues of employment and education particularly in people experiencing mobility problems and similar physical, sensory, or cognitive disabilities.

There are a number of clinical implications of this study. Firstly, regardless of the idiographic or client-centred nature of interventions in this area, facilitation of RTPR will be significantly more challenging for individuals who have more significant disabilities and cognitive challenges particularly involving language. There may be a role for more specific pre-vocational interventions that build up iteratively to scaffold into potential roles, similar to interventions for accessing new forms of employment (Simpson et al. 2018). Moreover, there may be a role for adjunctive social groups, which have been shown to enhance self-regulation skills in people with $A B I$ (Kinsella, et al. 2018). Such social groups may increase preparedness for RTPR, particularly given the observation that individuals who did not RTPR following their programme tended to be less integrated into their community at induction to their programme.

\section{Acknowledgement}

This study was funded by a grant from POBAL under the Disability Activation Programme.

\section{Disclosure statement}

No potential conflict of interest was reported by the author(s).

\section{Funding}

This work was supported by POBAL [Disability Activation Grant. DACT0013]. 


\section{References}

Balestreri, M., Czosnyka, M., Chatfield, D. A., Steiner, L. A., Schmidt, E. A., Smielewski, P., Matta, B., Pickard, J. D. (2004). Predictive value of Glasgow Coma Scale after brain trauma: Change in trend over the past ten years. Journal of Neurology, Neurosurgery \& Psychiatry, 75(1), 161-162.

Bender, R., \& Lange, S. (2001). Adjusting for multiple testing -when and how? Journal of Clinical Epidemiology, 2001(54), 343-349. https://doi.org/10.1016/S0895-4356(00)00314-0

Bonner, B., Pillai, R., Sarma, P. S., Lipska, K. J., Pandian, J., \& Sylaja, P. N. (2016). Factors predictive of return to work after stroke in patients with mild-moderate disability in India. European Journal of Neurology, 23(3), 548-553. https://doi.org/10.1111/ene.12887

Brasure, M., Lamberty, G. J., Sayer, N. A., Nelson, N. W., MacDonald, R., Ouellette, J., \& Wilt, T. J. (2013). Participation after multidisciplinary rehabilitation for moderate to severe traumatic brain injury in adults: A systematic review. Archives of Physical Medicine and Rehabilitation, 94(7), 1398-1420. https://doi.org/10.1016/j.apmr.2012.12.019

Bullard, S. E., Fein, D., Gleeson, M. K., Tischer, N., Mapou, R. L., \& Kaplan, E. (2004). The Biber cognitive estimation test. Archives of Clinical Neuropsychology, 19(6), 835-846. https://doi. org/10.1016/j.acn.2003.12.002

Cicerone, K. D., Mott, T., Azulay, J., \& Friel, J. C. (2004). Community integration and satisfaction with functioning after intensive cognitive rehabilitation for traumatic brain injury. Archives of Physical Medicine and Rehabilitation, 85(6), 943-950. https://doi.org/10.1016/j.apmr.2003. 07.019

Corrigan, J. D., \& Deming, R. (1995). Psychometric characteristics of the community integration questionnaire: Replication and extension. Journal of Head Trauma Rehabilitation, 10(4), 4153. https://doi.org/10.1097/00001199-199508000-00005

CSO. (2015, February 25). Quarterly National household Survey. Central Statistics Office.

Dawkins, N., Cloherty, M. E., Gracey, F., \& Evans, J. J. (2006). The factor structure of the Hospital Anxiety and Depression Scale in acquired brain injury. Brain Injury, 20(12), 1235-1239. https://doi.org/10.1080/02699050601076414

Dawson, D. R., Levine, B., Schwartz, M. L., \& Struss, D. T. (2004). Acute predictors of real-world outcomes following traumatic brain injury: A prospective study. Brain Injury, 18(3), 221-238. https://doi.org/10.1080/02699050310001617406

Donker-Cools, B. H. P. M., Daams, J. G., Wind, H., \& Frings-Dresen, M. H. W. (2016). Effective return-to-work interventions after acquired brain injury: A systematic review. Brain Injury, 30(2), 113-131. https://doi.org/10.3109/02699052.2015.1090014

Donker-Cools, B. H. P. M., Wind, H., \& Frings-Dresen, M. H. W. (2016). Prognostic factors of return to work after traumatic or non-traumatic acquired brain injury. Disability and Rehabilitation, 38(8), 733-741. https://doi.org/10.3109/09638288.2015.1061608

Drake, A. I., Gray, N., Yoder, S., Pramuka, M., \& Llewellyn, M. (2000). Factors predicting return to work following mild traumatic brain injury: A discriminant analysis. Journal of Head Trauma Rehabilitation, 15(5), 1103-1112. https://doi.org/10.1097/00001199-200010000-00004

Eakman, A. M., Atler, K. E., Rumble, M., Gee, B. M., Romriell, B., \& Hardy, N. (2018). A qualitative research synthesis of positive subjective experiences in occupation from the Journal of Occupational Science (1993-2010). Journal of Occupational Science, 25(3), 346-367. https://doi.org/10.1080/14427591.2018.1492958

Fabiano, R. J., \& Crewe, N. (1995). Variables associated with employment following severe traumatic brain injury. Rehabilitation Psychology, 40(3), 223-231. https://doi.org/10.1037/00905550.40.3.223

Fortune, D. G., \& Richards, H. L. (2017). Assessing cognitive estimation and its effects on community integration in people with acquired brain injury undergoing rehabilitation. BioMed Research International, 2017, 1-13. https://doi.org/10.1155/2017/2874819 
Fortune, D. G., Walsh, R. S., \& Richards, H. L. (2016). Cognitive reserve and preinjury educational attainment: Effects on outcome of community-based rehabilitation for longer-term individuals with acquired brain injury. International Journal of Rehabilitation Research, 39(3), 234239. https://doi.org/10.1097/MRR.0000000000000175

Fortune, D. G., Walsh, R. S., Waldron, B., McGrath, C., Harte, M., Casey, S., \& McClean, B. (2015). Changes in aspects of social functioning depend upon prior changes in neuro-disability in people with acquired brain injury undergoing post-acute neurorehabilitation. Frontiers in Psychology, Clinical Section, 6, 1-9. https://doi.org/10.3389/fpsyg.2015.01368

Franulic, A., Carbonell, C. G., Pinto, P., \& Sepulveda, I. (2004). Psychosocial adjustment and employment outcome 2, 5 and 10 years after TBI. Brain Injury, 18(2), 119-129. https://doi. org/10.1080/0269905031000149515

Garrelfs, S. F., Donker-Cools, B. H. P. M., Wind, H., \& Frings-Dresen, M. H. W. (2015). Return-towork in patients with acquired brain injury and psychiatric disorders as a comorbidity: A systematic review. Brain Injury, 29(5), 550-557. https://doi.org/10.3109/02699052.2014.995227

Girard, D., Brown, J., Burnett-Stolnack, M., Hashimoto, N., Hier-Wellmer, S., Perlman, O. Z., \& Seigerman, C. (1996). The relationship of neuropsychological status and productive outcomes following traumatic brain injury. Brain Injury, 10(9), 663-676. https://doi.org/10. 1080/026990596124089

Graham, C. W., West, M. D., Bourdon, J. L., Inge, K. J., \& Seward, H. E. (2016). Employment interventions for return to work in working aged adults following traumatic brain injury (TBI): $A$ systematic review. Campbell Systematic Reviews, 6. Campbell Collaboration.

Grauwmeijer, E., Heijenbrok-Kal, M. H., Haitsma, I. K., \& Ribbers, G. M. (2012). A prospective study on employment outcome 3 years after moderate to severe traumatic brain injury. Archives of Physical Medicine and Rehabilitation, 93(6), 993-999. https://doi.org/10.1016/j. apmr.2012.01.018

Howe, E. I., Andelic, N., Perrin, P. B., Røe, C., Sigurdardottir, S., Arango-Lasprilla, J. C., Lu, J., Løvstad, M., \& Forslund, M. V. (2018). Employment probability trajectories up to 10 years after moderate-to-severe traumatic brain injury. Frontiers in Neurology, 9, 1051. https:// doi.org/10.3389/fneur.2018.01051

Jamieson, M., Jack, R., O'Neill, B., Cullen, B., Lennon, M., Brewster, S., \& Evans, J. (2019). Technology to encourage meaningful activities following brain injury. Disability and Rehabilitation: Assistive Technology, 15, 1-14. https://doi.org/10.1080/17483107.2019. 1594402

Johansson, U., \& Bernspang, B. (2001). Predicting return to work after brain injury using occupational therapy assessments. Disability and Rehabilitation, 23(11), 474-480. https://doi.org/ 10.1080/09638280010010688

Kauranen, T., Turunen, K., Laari, S., Mustanoja, S., Baumann, P., \& Poutiainen, E. (2013). The severity of cognitive deficits predicts return to work after a first-ever ischaemic stroke. Journal of Neurology, Neurosurgery \& Psychiatry, 84(3), 316-321. https://doi.org/10.1136/ jnnp-2012-302629

Kean, J., Malec, J. F., Altman, I. M., \& Swick, S. (2011). Rasch measurement analysis of the MayoPortland Adaptability Inventory (MPAl-4) in a community-based rehabilitation sample. Journal of Neurotrauma, 28(5), 745-753. https://doi.org/10.1089/neu.2010.1573

Kinsella, E. L., Muldoon, O. T., Fortune, D. G., \& Haslam, C. (2018). Collective influences on individual functioning: Multiple group memberships, self-regulation, and depression after acquired brain injury. Neuropsychological Rehabilitation, 29, 1-15. https://doi.org/10.1080/ 09602011.2018 .1546194

Lamberty, G. J., Putnam, S. H., Chatel, D. M., \& Bieliauskas, L. A. (1994). Derived Trail Making test indices: A preliminary report. Neuropsychiatry, Neuropsychology, \& Behavioral Neurology, 7, 230-234. 
Larson, E., Kirschner, K., Bode, R., Heinemann, A., \& Goodman, R. (2005). Construct and predictive validity of the repeatable battery for the assessment of neuropsychological status in the evaluation of stroke patients. Journal of Clinical and Experimental Neuropsychology, 27(1), 16-32. https://doi.org/10.1080/138033990513564

Li-Wood, R., \& Rutterford, N. A. (2006). Demographic and cognitive predictors of long-term psychosocial outcome following traumatic brain injury. Journal of the International Neuropsychological Society, 12, 350-358. https://doi.org/10.1017/S1355617706060498

Lippa, S. M., Hawes, S., Jokic, E. Y., \& Caroselli, J. S. (2013). Sensitivity of the RBANS to acute traumatic brain injury and length of post-traumatic amnesia. Brain Injury, 27(6), 689-695. https:// doi.org/10.3109/02699052.2013.771793

Maas, A. I. R., Menon, D. K., Adelson, P. D., Andelic, N., Bell, M. J., Belli, A., Bragge, P., Brazinova, A., Büki, A., Chesnut, R. M., Citerio, G., Coburn, M., Cooper, D. J., Crowder, A. T., Czeiter, E., Czosnyka, M., Diaz-Arrastia, R., Dreier, J. P., Duhaime, A.-C., ... Zumbo, F. (2017). Traumatic brain injury: Integrated approaches to improve prevention, clinical care, and research. The Lancet Neurology, 16(12), 987-1048. https://doi.org/10.1016/S1474-4422(17)30371-X

Machamer, J., Temkin, N., Fraser, R., Doctor, J. N., \& Dikmen, S. (2005). Stability of employment after traumatic brain injury. Journal of the International Neuropsychological Society, 11(07), 807-816. https://doi.org/10.1017/S135561770505099X

Malec, J. F., Kean, J., Altman, I. M., \& Swick, S. (2012). Mayo-portland adaptability inventory: Comparing psychometrics in cerebrovascular accident to traumatic brain injury. Archives of Physical Medicine and Rehabilitation , 93(12), 2271-2275. https://doi.org/10.1016/j.apmr. 2012.06.013

Malec, J. F., Kean, J., \& Monahan, P. O. (2017). The minimal clinically important difference for the Mayo-Portland Adaptability Inventory. Journal of Head Trauma Rehabilitation, 32(4), E47-E54. https://doi.org/10.1097/HTR.0000000000000268

Malec, J.F. \& Lezak, M.D. (2008). Manual for the Mayo-Portland Adaptability Inventory. www. tbims.org/combi/mpai

McCrimmon, S., \& Oddy, M. (2006). Return to work following moderate-to-severe traumatic brain injury. Brain Injury, 20(10), 1037-1046. https://doi.org/10.1080/02699050600909656

McKay, C., Casey, J. E., Wertheimer, J., \& Fichtenberg, N. L. (2007). Reliability and validity of the RBANS in a traumatic brain injured sample. Archives of Clinical Neuropsychology, 22(1), 9198. https://doi.org/10.1016/j.acn.2006.11.003

Ntsiea, M. V., Van Aswegen, H., Lord, S., \& Olorunju S. S. (2015). The effect of a workplace intervention programme on return to work after stroke: A randomised controlled trial. Clinical Rehabilitation, 29(7), 663-673. https://doi.org/10.1177/0269215514554241

Odgaard, L., Johnsen, S. P., Pedersen, A. R., \& Nielsen, J. F. (2017). Return to work after severe traumatic brain injury: A nationwide follow-up study. The Journal of Head Trauma Rehabilitation, 32(3), E57-E64. https://doi.org/10.1097/HTR.0000000000000239

Ownsworth, T., \& McKenna, K. (2004). Investigation of factors related to employment outcome following traumatic brain injury: A critical review and conceptual model. Disability and Rehabilitation, 26(13), 765-783. https://doi.org/10.1080/09638280410001696700

Ponsford, J. L., Downing, M. G., Olver, J., Ponsford, M., Acher, R., Carty, M., \& Spitz, G. (2014). Longitudinal follow-up of patients with traumatic brain injury: Outcome at two, five, and ten years post-injury. Journal of Neurotrauma, 31(1), 64-77. https://doi.org/10.1089/neu.2013.2997

Ponsford, J. L., \& Spitz, G. (2015). Stability of employment over the first 3 years following traumatic brain injury. The Journal of Head Trauma Rehabilitation, 30(3), E1-E11. https://doi.org/ 10.1097/HTR.0000000000000033

Radford, K., Phillips, J., Drummond, A., Sach, T., Walker, M., Tyerman, A., Haboubi, N., \& Jones, T. (2013). Return to work after traumatic brain injury: Cohort comparison and economic evaluation. Brain Injury, 27(5), 507-520. https://doi.org/10.3109/02699052.2013.766929 
Randolph, C. (1998). Repeatable Battery for the Assessment of Neuropsychological Status (RBANS). The Psychological Corporation.

Rietdijk, R., Simpson, G., Togher, L., Power, E., \& Gillett, L. (2013). An exploratory prospective study of the association between communication skills and employment outcomes after severe traumatic brain injury. Brain Injury, 27(7-8), 812-818. https://doi.org/10.3109/ 02699052.2013 .775491

Ruet, A., Jourdan, C., Bayen, E., Darnoux, E., Sahridj, D., Ghout, l., Azerad, S., Pradat Diehl, P., Aegerter, P., Charanton, J., Vallat Azouvi, C., \& Azouvi, P. (2018). Employment outcome four years after a severe traumatic brain injury: Results of the Paris severe traumatic brain injury study. Disability and Rehabilitation, 40(18), 2200-2207. https://doi.org/10.1080/09638288.2017.1327992

Salter, K., McClure, J. A., Foley, N. C., \& Teasell, R. (2011). Community integration following TBI: An examination of community integration measures within the ICF framework. Brain Injury, 25(12), 1147-1154. https://doi.org/10.3109/02699052.2011.613088

Saltychev, M., Eskola, M., Tenovuo, O., \& Laimi, K. (2013). Return to work after traumatic brain injury: Systematic review. Brain Injury, 27(13-14), 1516-1527. https://doi.org/10.3109/ 02699052.2013.831131

Sánchez-Cubillo, l., Periáñez, J. A., Adrover-Roig, D., Rodríguez-Sánchez, J. M., Ríos-Lago, M., Tirapu, J., \& Barceló, F. (2009). Construct validity of the trail making test: Role of task-switching, working memory, inhibition/interference control, and visuomotor abilities. Journal of the International Neuropsychological Society, 15(3), 438-450. https://doi.org/10.1017/ S1355617709090626

Sawamura, D., Ikoma, K., Ogawa, K., \& Sakai, S. (2018). Clinical utility of neuropsychological tests for employment outcomes in persons with cognitive impairment after moderate to severe traumatic brain injury. Brain Injury, 32(13-14), 1670-1677. https://doi.org/10.1080/02699052. 2018.1536281

Schonberger, M., \& Ponsford, J. (2010). The factor structure of the Hospital anxiety and depression scale in individuals with traumatic brain injury. Psychiatry Research, 179(3), 342-349. https://doi.org/10.1016/j.psychres.2009.07.003

Schonbrun, S., \& Kampfe, C. (2004). Variables relating to employment outcome in individuals with traumatic brain injury. Journal of Applied Rehabilitation Counseling, 35(3), 14-21. https://doi.org/10.1891/0047-2220.35.3.14

Sigurdardottir, S., Andelic, N., Wehling, E., Anke, A., Skandsen, T., Holthe, O. O., \& Manskow, U. S. (2020). Return to work after severe traumatic brain injury: A national study with a one-year follow-up of neurocognitive and behavioural outcomes. Neuropsychological Rehabilitation, 30, 281-297. https://doi.org/10.1080/09602011.2018.1462719

Silverberg, N. D., Panenka, W. J., \& Iverson, G. L. (2018). Work productivity loss after mild traumatic brain injury. Archives of Physical Medicine and Rehabilitation, 99(2), 250-256. https:// doi.org/10.1016/j.apmr.2017.07.006

Simpson, G.K., McRae, P., Hallab, L., Daher, M. \& Strettles, B. (2018). Participation in competitive employment after severe traumatic brain injury: New employment versus return to previous (pre-injury) employment. Neuropsychological Rehabilitation, 1-18. https://doi.org/10.1080/ 09602011.2018.1531769

Treger, I., Shames, J., Giaquinto, S., \& Ring, H. (2007). Return to work in stroke patients. Disability and Rehabilitation, 29(17), 1397-1403. https://doi.org/10.1080/09638280701314923

UK Office for National Statistics. (2008). The Standard Occupational Classification 2000 (SOC2000). http://www.ons.gov.uk/ons/guide-method/classifications/archived-standardclassifications/standard-occupational-classification-2000/about-soc-2000/index.html

van der Horn, H. J., Spikman, J. M., Jacobs, B., \& van der Naalt, J. (2013). Postconcussive complaints, anxiety, and depression related to vocational outcome in minor to severe traumatic 
brain injury. Archives of Physical Medicine and Rehabilitation, 94(5), 867-874. https://doi.org/ 10.1016/j.apmr.2012.11.039

van der Kemp, J., Kruithof, W. J., Nijboer, T. C., van Bennekom, C. A., van Heugten, C., \& VisserMeily, J. M. (2019). Return to work after mild-to-moderate stroke: Work satisfaction and predictive factors. Neuropsychological Rehabilitation, 29(4), 638-653. https://doi.org/10.1080/ 09602011.2017.1313746

van Velzen, J. M., van Bennekom, C. A., Edelaar, M. J., Sluiter, J. K., \& Frings-Dresen, M. H. (2009a). Prognostic factors of return to work after acquired brain injury: A systematic review. Brain Injury, 23(5), 385-395. https://doi.org/10.1080/02699050902838165

van Velzen, J. M., van Bennekom, C. A., Edelaar, M. J., Sluiter, J. K., \& Frings-Dresen, M. H. (2009b). How many people return to work after acquired brain injury? A systematic review. Brain Injury, 23(6), 473-488. https://doi.org/10.1080/02699050902970737

Wang, V., Fort, E., Beaudoin-Gobert, M., Ndiaye, A., Fischer, C., Bergeret, A., .. Luauté, J. (2019). Indicators of long-term return to work after severe traumatic brain injury: A cohort study. Annals of Physical and Rehabilitation Medicine, 62(1), 28-34. https://doi.org/10.1016/j. rehab.2018.08.003

Wilde, M. C. (2010). Lesion location and repeatable battery for the assessment of neuropsychological status performance in acute ischemic stroke. The Clinical Neuropsychologist, 24(1), 57-69. https://doi.org/10.1080/13854040902984505

Willemse-van Son, A. H., Ribbers, G. M., Verhagen, A. P., \& and Stam, H. J. (2007). Prognostic factors of long-term functioning and productivity after traumatic brain injury: A systematic review of prospective cohort studies. Clinical Rehabilitation, 21(11), 1024-1037. https://doi. org/10.1177/0269215507077603

Zigmond, A. S., \& Snaith, R. P. (1983). The hospital anxiety and depression scale. Acta Psychiatrica Scandinavica, 67(6), 361-370. doi:10.1111/j.1600-0447.1983.tb09716.x 